\section{$\underset{\substack{\text { hommes } \\ \text { \& migrations }}}{ }$}

\section{Hommes \& migrations}

Revue française de référence sur les dynamiques

migratoires

$1278 \mid 2009$

Histoire des immigrations. Panorama régional

\title{
35 rhums
}

Film français de Claire Denis

\section{André Videau}

\section{Q OpenEdition \\ 1 Journals}

\section{Édition électronique}

URL : http://journals.openedition.org/hommesmigrations/269

DOI : 10.4000/hommesmigrations.269

ISSN : 2262-3353

Éditeur

Musée national de l'histoire de l'immigration

\section{Édition imprimée}

Date de publication : 1 mars 2009

Pagination : 257-258

ISSN : $1142-852 X$

\section{Référence électronique}

André Videau, « 35 rhums », Hommes \& migrations [En ligne], 1278 | 2009, mis en ligne le 29 mai 2013, consulté le 22 septembre 2020. URL : http://journals.openedition.org/hommesmigrations/269 ; DOI : https://doi.org/10.4000/hommesmigrations.269

Ce document a été généré automatiquement le 22 septembre 2020.

Tous droits réservés 


\title{
35 rhums
}

\author{
Film français de Claire Denis
}

\section{André Videau}

1 Lionel et Joséphine vivent dans leur appartement de la banlieue nord comme un couple bien rangé. Chaque chose a sa place : les vêtements de rechange accrochés à la patère, les pantoufles prêtes à chausser, les provisions et les ustensiles de cuisine à portée de main, dont l'indispensable autocuiseur, révélateur de la nature antillaise du sacro-saint repas du soir. Sauf qu'ils ne sont pas un couple au sens sociobiologique du terme. Lionel, veuf, la cinquantaine puissante (le magnétique Alex Descas, interprète référent de plusieurs films de Claire Denis, dont S'en fout la mort, en 1990, J'ai pas sommeil, en 1994, Nénette et Boni, en 1997), est conducteur de RER. Joséphine, sa fille, est une jeune et jolie étudiante sans histoire (débuts prometteurs de Mati Diop).

2 La relation entre le père et la fille a beau être intense et pour ainsi dire fusionnelle, on sent que les rôles sont distribués depuis trop longtemps, que l'usure, ici ou là, se manifeste, que chacun des deux protagonistes aspire à des changements ou, du moins, les envisage sans trop en craindre les bouleversements. Il y a des indices qui ne peuvent tromper éternellement. Il y a cet étudiant sérieux qui fréquente Joséphine et auquel elle n'est pas insensible, même s'il n'est pas l'homme de sa vie. Il y a ce collègue mélancolique qui prend sa retraite et découvre que le temps avance à grands pas et qui, sans qu'on y prenne garde, va franchir les limites de la désespérance. Il y a même des indices matériels encore plus incontournables : l'achat d'un deuxième autocuiseur aux couleurs pimpantes, premier élément pour fonder un autre ménage, ailleurs.

3 Avec une délicatesse frémissante, sorte de sismographe sentimental et charnel, Claire Denis, magnifiquement secondée par l'écriture de Jean-Pol Fargeau et les images d'Agnès Godard, enregistre les troubles avant la tempête, dont rien ne dissipera l'inexorable issue. Ni l'entrée en jeu de comparses incapables de changer la donne: ainsi de Gabrielle, chauffeur de taxi à ses heures, amie et voisine et pas plus sans affinités (Nicole Dogue, touchante cariatide au balcon de l'immeuble qui grille cigarette sur cigarette pour que son spleen parte en fumée), ainsi de Noé (Grégoire Colin, Pierrot lunaire et éméché - un 
autre des acteurs fraternels de la réalisatrice dont chaque nouveau rôle patine l'innocence des débuts, transformée en force irradiante).

4 On peut encore provoquer quelques diversions, comme cette balade vers la sépulture de la mère pour revigorer l'intimité - dans une sorte de voyage-pèlerinage à Lübeck en Allemagne, loin de nos banlieues trop prévisibles - et rendre visite à une tante pythie. Quelques minutes de grâce absolue confiées à Ingrid Caven.

5 Et rien de pire pour achever le fiasco qu'une virée du samedi soir, un concert raté, une panne, une tornade (n'en jetez plus!) et le repli en catastrophe dans un bar complice. La fête impromptue. Les épices qui brûlent. Les corps qui tanguent. L'alcool qui détruit tout sur son passage. Comment tenir encore le coup face aux 35 verres de rhum alignés sur le comptoir, peut-être imposés par les coutumes, entre "ça s'arrose" et "cul sec", peut-être inventés par Claire Denis pour mettre au compte d'un père flibustier, chagriné de se séparer de sa fille?

6 Pour dissiper les brumes de l'âme, notre réalisatrice la plus africaine a fait un film aux inflexions et aux penchants asiatiques, jusqu'aux beuveries, jusqu'à l'ivresse.

7 J'allais oublier de préciser que peut-être tous les personnages sont noirs.

8 Ça n'a vraiment aucune importance. 